\title{
Ornithonyssus spp.
}

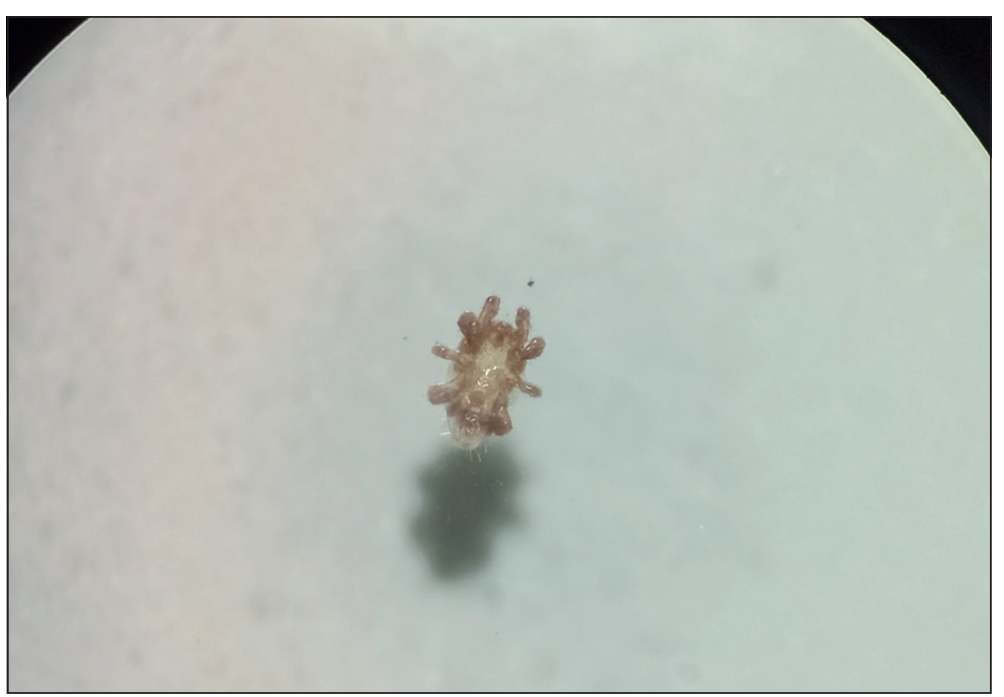

Figura 1. Ácaro de Ornithonyssus sp. extraído de una paciente con dermatitis facial que estuvo en contacto con palomas infestadas. Lupa estereoscópica 10X.

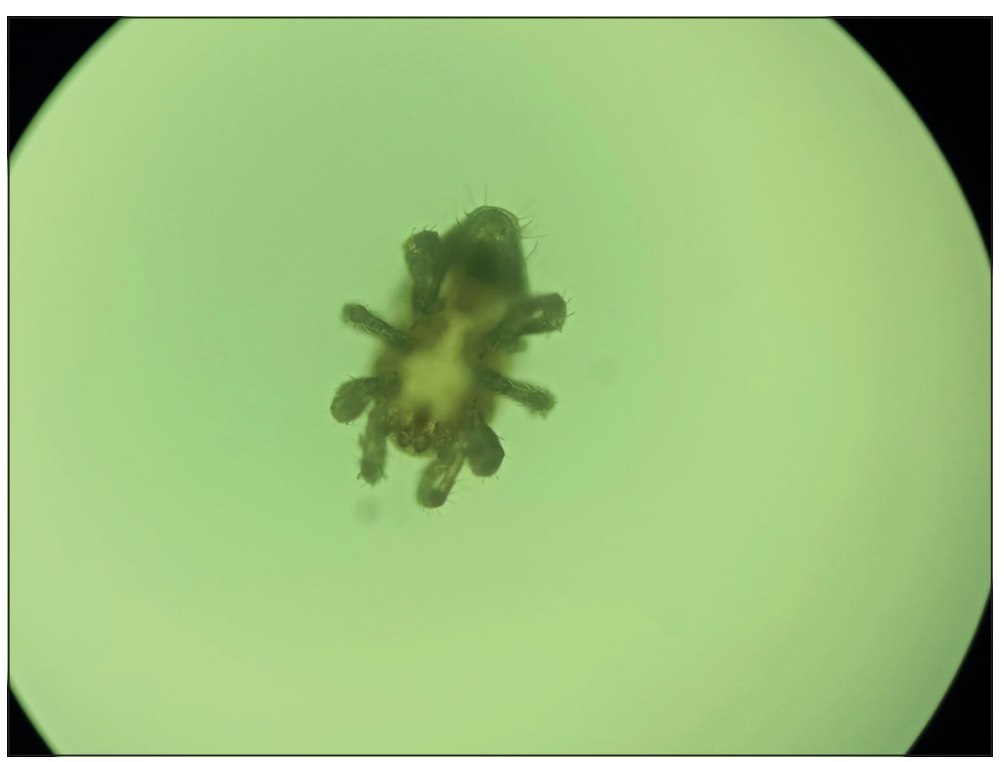

Figura 2. Ácaro de Ornithonyssus sp. Microscopía de luz 10X. 


\section{Ornithonyssus spp.}

El género Ornithonyssus, perteneciente a la familia Macronyssidae y al orden Mesostigmata, constituye un grupo de ácaros hematófagos obligados, que habitan en contacto directo con diversos hospederos, tales como aves, mamíferos (roedores y murciélagos) y reptiles. Si bien se han descrito diversas especies, principalmente en Brasil, la escasa literatura especializada se concentra prácticamente en solo tres: O. sylviarium, O. bacoti, y O. bursa, debido a su impacto epidemiológico y en la salud humana.

Las especies $O$. sylviarium y $O$. bursa afectan principalmente a las aves y su importancia radica en las graves pérdidas que pueden provocar en la industria avícola. Los ácaros de $O$. sylviarium habitan el cuerpo del ave, y además se pueden encontrar en los nidos, jaulas y su entorno. El ciclo de vida se desarrolla completamente en el huésped y los ácaros pueden sobrevivir hasta tres semanas en el medioambiente. Se considera un vector para el virus de la encefalitis de San Luis y encefalitis equina del oeste. La especie $O$. bursa o "ácaro tropical de las gallinas", a diferencia de $O$. sylviarium, desarrolla su ciclo de vida en los nidos y no sobrevive más de 10 días fuera de su hospedero. Estas especies, al entrar en contacto accidental con el humano, pueden provocar lesiones papulares, papulo-vesiculares o urticariales pruriginosas.

La especie $O$. bacoti afecta principalmente a las ratas ("ácaro tropical de las ratas") y su importancia radica en su potencial rol como vector de patógenos de enfermedades infecciosas de importancia en humanos, tales como fiebre hemorrágica, encefalitis, tularemia, peste, tifus endémico, rickettsiosis, bartonelosis y leptospirosis. También puede provocar cuadros alérgicos cutáneos y respiratorios, siendo una causa de asma ocupacional en trabajadores avícolas.

La identificación de estos ácaros se basa principalmente en los aspectos morfológicos. Respecto a las especies $O$. sylviarium y $O$. bursa, las principales diferencias son: margen posterior del escudo dorsal más estrecho y dos pares de setas en el escudo esternal en $O$. sylviarium, versus tres pares de setas en $O$. bursa, el cual es más ancho en el margen posterior del escudo dorsal. El tamaño fluctua entre 0,6 y $1 \mathrm{~mm}$ de largo.

Respecto al manejo de estas acarosis, la principal medida es erradicar la infestación en aves de corral u otras especies, además de aplicar medidas de saneamiento ambiental. Puede entrar en contacto directo con el ser humano, sin embargo, no se encuentran adaptados para una infestación prolongada.

\section{Referencias bibliográficas}

1.- Jofré L, Noemí I, Neira P, Saavedra T, Díaz C. Acarosis y zoonosis relacionadas. Rev Chilena Infectol 2009; 26: 248-57. doi: 10.4067/ S0716-10182009000400008.

2.- $\quad$ Nieri-Bastos F A, Labruna M B, Marcili A, Durden L A, Mendoza-Uribe L, Barros-Battesti D M. Morphological and molecular analysis of Ornithonyssus spp. (Acari: Macronyssidae) from small terrestrial mammals in Brazil. Exp Appl Acarol 2011; 55: 305-27. doi: 10.1007 / s10493-011-9475-z.

3.- Bhuyan P J, Nath A J. Record of tropical rat mite, Ornithonyssus bacoti (Acari: Mesostigmata: Macronyssidae) from domestic and peridomestic rodents (Rattus rattus) in Nilgiris, Tamil Nadu, India. J Arthropod Borne Dis 2015; 10: 98-101.

4.- Murillo A C, Mullens B A. A review of the biology, ecology, and control of the northern fowl mite, Ornithonyssus sylviarum (Acari: Macronyssidae). Vet Parasitol 2017; 246: 30-7. doi: 10.1016/j.vetpar.2017.09.002.

5.- Bassini-Silva R, de Castro Jacinavicius F, Hernandes FA, Ochoa R, Bauchan GR, Dowling APG, et al. Dermatitis in humans caused by Ornithonyssus bursa (Berlese 1888) (Mesostigmata: Macronyssidae) and new records from Brazil. Rev Bras Parasitol Vet 2019; 28: 134-9. doi: 10.1590/s1984-296120180097.

Yerko Leiva ${ }^{1}$, Paula Hasbún Acuña ${ }^{2}$, Rodrigo Cruz Choapa ${ }^{1}$ ${ }^{1}$ Centro de Diagnóstico e Investigación de Enfermedades Infecciosas (CDIEI), Universidad de Valparaíso, Chile. ${ }^{2}$ Dermatología, Universidad de Los Andes, Chile. 